\title{
Estudio del comportamiento del Índice de Precios y Cotizaciones y Emisoras en México
}

\author{
Index of Prices and Quotations and Mexican Issuer Organizations`Behavioral Study \\ Magda Gabriela Sánchez Trujillo ${ }^{a}$
}

\begin{abstract}
:
The stock exchange is one of the most important financial markets, whose behavior reflects the fluctuations of the IPC. That is why studying its dynamics makes it necessary to take financial decisions based on the index's financial performance.

Keywords:

issuing companies, stock exchange, Ebitda, profit

\section{Resumen:}

El mercado bursátil es uno de los más importantes mercados financieros, cuyo comportamiento refleja las fluctuaciones del mercado accionario. Es por ello que estudiar su dinámica lo vuelve obligado para toma de decisiones de analistas o asesores financieros que buscan realizar transacciones de compra venta de valores con base en los rendimientos del índice de precios y cotizaciones de las emisoras que participan.
\end{abstract}

\section{Palabras Clave:}

emisoras, bolsa de valores, ebitda, utilidad

\section{Introducción}

La bolsa de valores funciona bajo una dinámica de mercado, en el que la interacción entre oferentes y demandantes influye en el comportamiento de los precios. El Índice de Precios y Cotizaciones (IPC) es el principal índice bursátil de la Bolsa Mexicana de Valores (BMV), primordial censor que permite conocer las fluctuaciones del mercado accionario mexicano ya que agrupa las empresas emisoras con mayor liquidez, las cuales muestran el comportamiento y dinámica de la BMV. La BMV es la segunda bolsa más grande de América Latina con una capitalización total de mercado de más de US \$ 530 mil millones.

Para formar parte de la muestra del IPC, las emisoras deben cumplir con diversos criterios de representatividad en el mercado tales como:

- $\quad$ Tiempo mínimo de operación continua

- $\quad$ Porcentaje de acciones flotantes mínimo

\footnotetext{
* Capitalización flotada. También conocido como Valor de Capitalización ajustado por acciones flotantes, es el valor
}

- Series accionarias cuyo valor de capitalización flotado, considerando el precio promedio ponderado de los últimos tres meses, sea igual o mayor al $0.1 \%$ del valor de capitalización, ponderado de los últimos tres meses, de la muestra del IPC

- De las 55 series accionarias que tienen el mayor factor de rotación, medido como la mediana de medianas mensuales de la rotación relativa al importe acumulado durante los 12 meses previos al mes de revisión de la muestra.

- Calificación conjunta del factor de rotación, (medido como la mediana de medianas mensuales de la rotación relativa al importe acumulado durante los 12 meses previos al mes de revisión de la muestra), el valor de capitalización flotado*, y la mediana de medianas mensuales del importe operado en Bolsa en los 12 meses previos al mes de revisión de la muestra (BMV, 2017).

La muestra del IPC de la Bolsa Mexicana de Valores es revisada anualmente, el número de series de acciones que conforma la muestra es de 35 , las cuales son

que resulta de multiplicar el número de acciones flotantes de la serie accionaria por el precio de mercado de la acción. 
revisadas cada seis meses y sustituidas en función a los criterios de selección mencionados con anterioridad. Ninguna emisora tiene un peso mayor al $25 \%$ en el índice, y la suma de las 4 principales emisoras no exceden el $60 \%$ del índice. Las emisoras que forman parte del Índice de Precios y Cotizaciones de México durante el periodo Septiembre 2016 a Agosto 2017 son ordenadas por su peso en el índice, Este es un grupo de intercambio totalmente integrado que opera en efectivo, derivados cotizados y mercados extrabursátiles para múltiples clases de activos, incluyendo acciones, renta fija y fondos cotizados, así como también instalaciones de custodia, compensación y liquidación y productos (Tabla1).

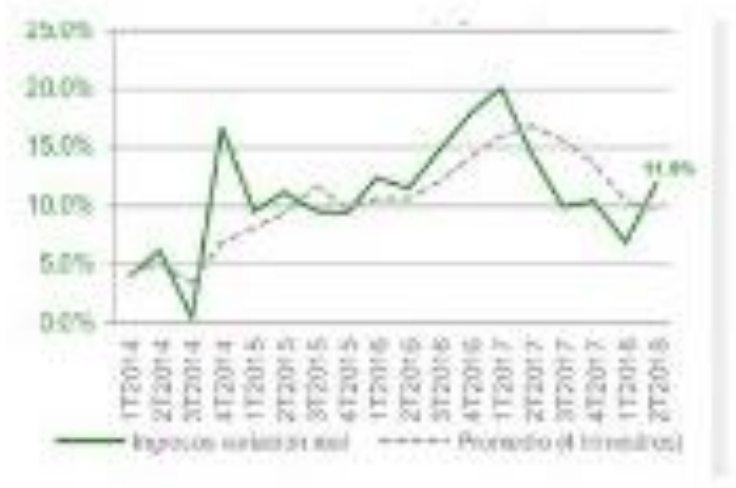

Tabla 1. Emisoras IPC. Fuente: CI Banco

Ingresos de Emisoras IPC

El indicador financiero para medir los ingresos es el Ebitda* beneficios antes de intereses, impuestos, depreciación y amortización de la empresa. Los resultados en ingresos son explicados por adquisiciones, mayores precios en productos o servicios de venta y estabilidad general en los volúmenes.

Los resultados de los reportes del 2trimestre 2018 de las empresas que conforman el IPC fueron positivos superando las expectativas del mercado, dando como resultado un crecimiento anual en ingresos netos de $11.9 \%$ (+7.7\% esperado), luego de tres trimestres de desaceleración en el ritmo de crecimiento en 2017. (Gráfica1).

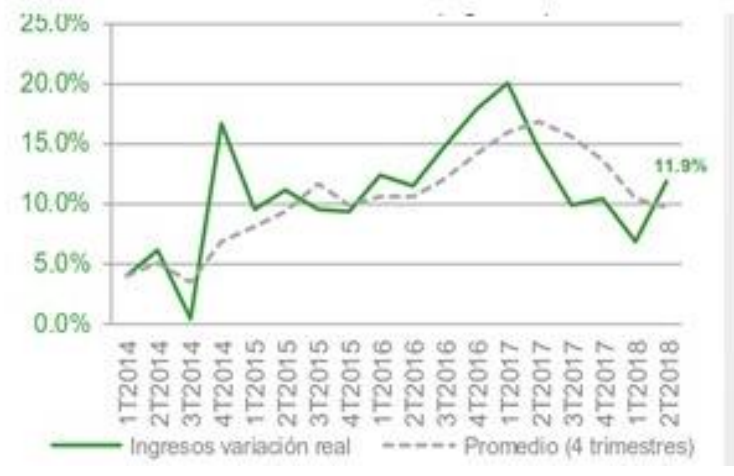

Gráfica 1. Variación anual real (ingresos). Cl análisis y Thomson Reuters

\section{El Ebitda}

La muestra de emisoras presenta en el mismo periodo incremento de $17.6 \%(+12.3 \%$ esperado) y la utilidad neta se expandió $23.1 \%$ (-4.1\% esperado). Analistas expertos coinciden que el buen resultado operativo es derivado de la fortaleza en los ingresos, los cuales compensaron presiones de costos y gastos. Por su parte, la utilidad neta se vio favorecida por la mejora generalizada en las ganancias operativas y cambiarias, compensando mayores gastos por intereses e impuestos a la utilidad (Grafica 2).

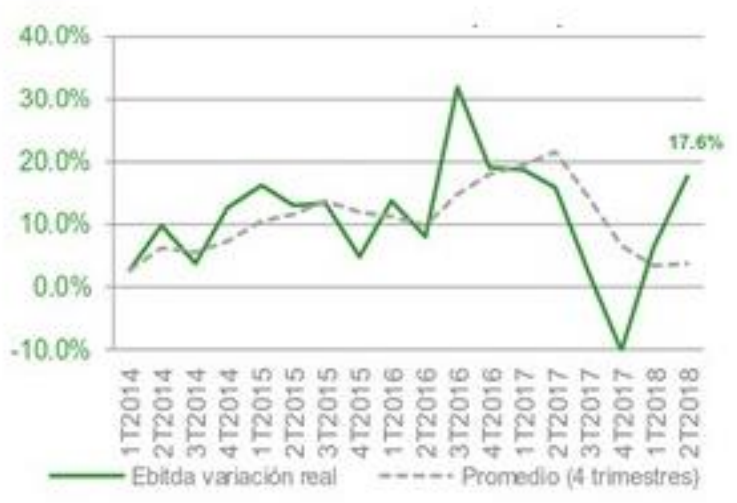

Gráfica 2. Variación anual real (Ebitda). Cl análisis y Thomson Reuters

En estas variaciones positivas de tres trimestres, 14 empresas lograron superar la tasa de crecimiento de Ebidta de la muestra en su conjunto. Las emisoras con los mejores reportes en el segundo cuarto del año fueron: ALPEK, MEXCHEM, TLEVISA, ALFA y GMEXICO. En sentido opuesto, las emisoras con reportes bajos fueron: VOLAR, AMX, GENTERA, BIMBO y KOF

\footnotetext{
* Su nombre deviene de las siglas en inglés de earnings before interest, taxes, depreciation and amortization
} 
Por su parte la utilidad neta de la actual muestra del IPC presentó un fuerte recuperación (agravada por la depreciación de la moneda mexicana frente al dólar), rompiendo con la tendencia negativa iniciada en el 2 Trimestre de 2017. De esta manera la utilidad neta se expandió $23.1 \%$ anual. De la muestra de 35 empresas, ninguna reportó pérdidas netas. De esta manera, emisoras de peso importante como: FEMSA, CEMEX, TELEVISA y

GMEXICO reportaron crecimientos de doble dígito (Grafica 3).

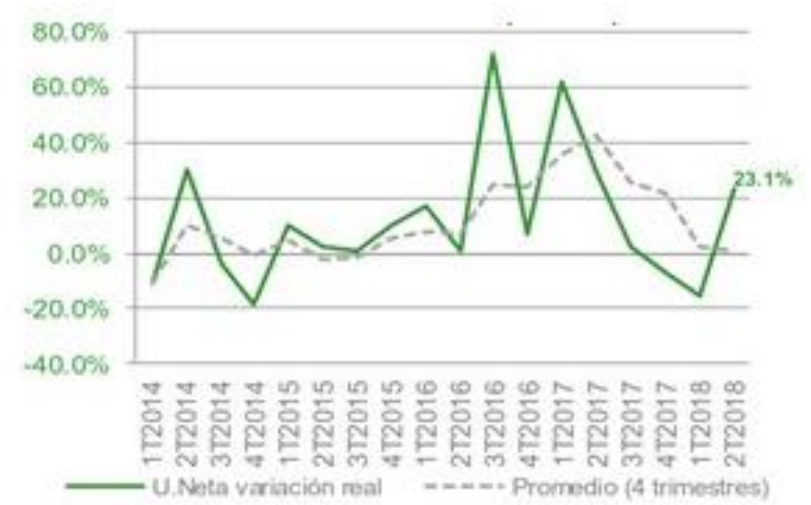

Grafica 3. Variación anual real de utilidad. Cl análisis y Thomson Reuters

\section{Conclusiones}

En términos generales, los resultados de los reportes del segundo trimestre de 2018 de las empresas que conforman el IPC fueron positivos y mejores a lo esperado por el mercado. A nivel operativo los reportes estuvieron en línea con lo estimado, impulsado por el consumo en general, así como por aspectos macroeconómicos internos y externos, como adquisiciones realizadas por algunas empresas, la mejora en el precio de ciertos commodities $^{*}$ y la debilidad del peso frente al dólar que benefició a las firmas exportadoras o con operaciones en monedas duras ${ }^{\dagger}$ (dólar y euro).

Sin embargo en el inicio de tercer semestre 2018 el mercado accionario opera un volumen de 843,475 títulos, por un importe económico de 22.9 millones de pesos, en donde participan 44 emisoras, 21 ganan, 19 pierden y cuatro se mantienen sin cambios.

A nivel mundial se observan fluctuaciones negativas, con una mayor prevención al riesgo hacia los mercados emergentes, así como temas de comercio internacional en

\footnotetext{
* Cuando se habla de commodities, se refiere a materias primas o bienes primarios.

$\dagger$ Moneda dura es aquella que se cambia libremente y cuyo valor no se depreciará en el futuro previsible. Las monedas fuertes
}

Manufacturas y Gasto en Construcción y acuerdos para renovar en TLCAN.

\section{Referencias}

Anaya, Jessica (2000). Introducción a los derivados, México: Prentice Hall.

Bolsa Mexicana de Valores. (2018). Índices de mercado. Recuperado de http://www.bmv.com.mx/es/indices/principales/

CI Banco. Análisis económico financiero (2018). Recuperado de: http://www.cibanco.com/es/cibanco/analisis-financiero-economico

El mercado mexicano de dinero, capitales y productos derivados: Sus instrumentos y usos (1998), México, Grupo Asesores Financieros, Thomson Financial Services - Editorial Eón. suelen contar con una demanda elevada y su tipo de cambio tiende a aumentar debido a su alta demanda con respecto a su oferta. 